\title{
Possible modulation of FAS and PTP-1B signaling in ameliorative potential of Bombax ceiba against high fat diet induced obesity
}

\author{
Paras Gupta ${ }^{1}$, Rohit Goyal2 ${ }^{2}$, Yamini Chauhan ${ }^{2}$ and Pyare Lal Sharma ${ }^{1}$
}

\begin{abstract}
Background: Bombax ceiba Linn., commonly called as Semal, is used in various gastro-intestinal disturbances. It contains Lupeol which inhibits PTP-1B, adipogenesis, TG synthesis and accumulation of lipids in adipocytes and adipokines whereas the flavonoids isolated from B. ceiba has FAS inhibitory activity. The present study was aimed to investigate ameliorative potential of Bombax ceiba to experimental obesity in Wistar rats, and its possible mechanism of action.

Methods: Male Wistar albino rats weighing 180-220 g were employed in present study. Experimental obesity was induced by feeding high fat diet for 10 weeks. Methanolic extract of B. ceiba extract 100, 200 and $400 \mathrm{mg} / \mathrm{kg}$ and Gemfibrozil $50 \mathrm{mg} / \mathrm{kg}$ as standard drug were given orally from $7^{\text {th }}$ to $10^{\text {th }}$ week.

Results: Induction with HFD for 10 weeks caused significant $(p<0.05)$ increase in \% body wt, BMI, LEE indices; serum glucose, triglyceride, LDL, VLDL, cholesterol, free fatty acid, ALT, AST; tissue TBARS, nitrate/nitrite levels; different fat pads and relative liver weight; and significant decrease in food intake ( $\mathrm{g}$ and $\mathrm{kcal}$ ), serum HDL and tissue glutathione levels in HFD control rats. Treatment with B. ceiba extract and Gemfibrozil significantly attenuated these HFD induced changes, as compared to HFD control. The effect of B. ceiba 200 and $400 \mathrm{mg} / \mathrm{kg}$ was more pronounced in comparison to Gemfibrozil.

Conclusion: On the basis of results obtained, it may be concluded that the methanolic extract of stem bark of Bombax ceiba has significant ameliorative potential against HFD induced obesity in rats, possibly through modulation of FAS and PTP-1B signaling due to the presence of flavonoids and lupeol.
\end{abstract}

Keywords: Obesity, Bombax ceiba, Free fatty acid, Protein tyrosine phosphatase-1B, Fatty acid synthase

\section{Background}

Obesity is one of the leading causes of death worldwide [1] and characterized by excess body fat accumulation [2]. It is a chronic disorder with complex interaction between genetic and environmental factors and occurs due to increased intake of high fat and energy food with decreased energy expenditure. Endogenous involvement of leptin, insulin, ghrelin, CCK (cholecystokinin), NPY (neuropeptide Y), GLP-1 (glycogen like peptide 1) and PTP-1B (protein tyrosine phosphate-1B) signaling has potential effect on food intake and energy expenditure [3]. The stimulation

\footnotetext{
* Correspondence: rohit_pharm@yahoo.co.in

${ }^{2}$ School of Pharmaceutical Sciences, Shoolini University, Solan, HP 173212, India

Full list of author information is available at the end of the article
}

of PTP-1B also modulates insulin, leptin and integrin signaling, and thereby stimulates fatty acid synthase (FAS) activity and results obesity [4,5]. According to Ayurveda, vitiations in three body humours i.e. tridoshas (vata, pitta and kapha) is characterized by altered body functions like metabolism, digestion, appetite and thus precipitates obesity [6]. The clinical claims revealed that the obesity is caused due to genetic predisposition and improper life style.

The traditional system of medicine has incorporated use of medicinal plant drugs or formulation for the prevention of obesity. Bombax ceiba Linn., belongs to family Malvaceae, commonly called as semal, shimbal (in hindi) and red silk cotton tree (in english) [7]. The stem bark is reported to contain lupeol, shamimicin, flavonoids, glycoside,

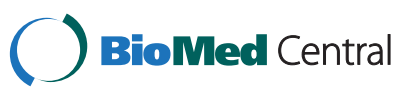


sterol: $\beta$-sitosterol, terpenoids, napthol, hemigossylic acid and lactone-7-methyl ether [8,9]. Shamimin (C-flavonol glucoside) isolated from $B$. ceiba methanolic extract showed significant hypotensive and hypoglycaemic properties and was found to be safe in rodents [9]. Mangiferin obtained from methanolic extract of B. ceiba leaves demonstrated strong antioxidant and hepatoprotective activities [10]. Ethno-pharmacologically, it is used to treat diarrhea, dysentery, digestive disturbances, diabetes [11] and improves digestion (Jain, 1996). In ayurveda, B. ceiba is generally recommended to use in vitiated conditions of vata, pitta and kapha and removes pitta and kappa [12]. It has a potent free radical scavenging [13], anti-inflammatory and hepatoprotective activities $[8,14]$. The flavonoids isolated from B. ceiba have a potent FAS inhibitory activity [15]. Lupeol, found in B. ceiba inhibits PTP-1B, adipogenesis, TG synthesis and accumulation of lipids in adipocytes and adipokines [16].

On the basis of literature available, we hypothesized to investigate the possible anti-obesity potential of Bombax ceiba in high fat diet-induced experimental obesity, possibly due to the involvement of FAS and PTP-1B signaling in present study.

\section{Methods}

Collection, authentication and extraction of plant material Bombax ceiba Linn. stem bark was collected from Gwalior, MP, India, authentified from NISCAR, New Delhi under consultation with Dr. H.B. Singh, Director and a voucher specimen of plant drug sample was deposited in institutional herbarium (NISCAIR/RHMD/Consult/-20011-12/ 1758/58). Stem bark was shade dried, coarsely powdered and stored in air tight container till further use. The literature revealed that the phytoconstituents isolated from methanolic extract of $B$. ceiba have potent biological efficacies. Therefore, plant drug extraction was made with soxhlet extractor using methanol as solvent.

\section{Phytochemical screening}

The qualitative phytochemical screening of B. ceiba extract was carried out for the presence of phytoconstituents like steroids, terpenoids, anthraquinone glycosides, Cglycosides, cardiac glycosides, flavonoids, tannins, phenolic and carbohydrates [17].

\section{Acute toxicity study}

Acute toxicity study of $B$. ceiba extract was conducted as per the Organization for Economic Co-operation and Development (OECD) 423 guidelines: acute toxicity class method [18] using Wistar albino rats $(n=3)$. B. ceiba extract (methanolic) was given orally in doses: 50, 100, 300,1000 and $2000 \mathrm{mg} / \mathrm{kg}$; suspended in $0.5 \% \mathrm{CMC}$ solution and the animals were observed for physiological (body wt, urination, pellet expulsion and salivation), behavioral (irritability, corneal reflex, catatonia, locomotion, convulsion and tremor), biochemical (serum ALT, AST and glucose) and toxic manifestations and even mortality, if any, up to 14 days.

\section{Chemicals and reagents}

Casein from Modern Dairy, New Karnal, India; cholesterol from Thomas Baker; and Gemfibrozil from Pfizer, USA were purchased. The biochemical enzymatic kits were purchased from Coral Diagnostics Ltd., Mumbai, India. All other chemicals/reagents used were of analytical grade and were freshly prepared before use.

\section{Animals}

Male, Wistar albino rats, weighing 180-220 g were employed in present study. They were fed on standard chow diet (Ashirwad Industries Private Ltd., Ropar, Punjab, India) and water ad libitum; and maintained at 12-12 h light/dark cycles, temperature $25 \pm 2{ }^{\circ} \mathrm{C}$ and relative humidity $55 \pm 5 \%$. The experimental protocol was duly been approved by Institutional Animal Ethics Committee (IAEC) and the experimentations were conducted under the guidelines from Committee for the purpose of Control and Supervision of Experiments on Animals (CPCSEA).

\section{High fat diet-induced obesity}

Experimental obesity was developed by feeding high fat diet (Powdered Normal Chow, 365 g; lard, 310 g; casein, 250 g; cholesterol, $10 \mathrm{~g}$; vitamin mix and mineral mix, $60 \mathrm{~g}$; dl-methionine, $03 \mathrm{~g}$; yeast powder, $01 \mathrm{~g}$; and $\mathrm{NaCl}$, $01 \mathrm{~g}$ were mixed to prepare $1.0 \mathrm{~kg}$ of HFD) [19], to rats for 10 weeks. The High fat diet contains $5.33 \mathrm{kcal} / \mathrm{g}$ while the normal chow contains $3.80 \mathrm{kcal} / \mathrm{g}$.

\section{Experimental protocol}

All animals were divided into different groups each comprising six animals $(n=6)$. The groups were 1$)$. Normal control receiving vehicle only; 2). HFD control receiving high fat diet for 10 weeks; 3). Gemfibrozil-50 receiving gemfibrozil $50 \mathrm{mg} / \mathrm{kg}$ as standard; 4), 5), 6) B.C. 100 or 200 or 400 receiving $B$. ceiba extract 100, 200 and $400 \mathrm{mg} / \mathrm{kg}$ respectively. Administration of vehicle, standard and the plant extracts were done orally from $7^{\text {th }}$ week to 10 week by suspending in $0.5 \%$ CMC solution as vehicle. After completion of experimental protocol, pahramcological assessments shall be carried out. Animals were anaesthetized, blood was collected from retro orbital plexuses, centrifuged and serum separated for biochemical estimations. Animals were sacrificed, and liver and different fat depots were surgically dissected out. $10 \%$ liver homogenate was prepared in $0.1 \mathrm{M}$ Tris buffer $(\mathrm{pH}=7.4)$ or phosphate buffer $(0.1 \mathrm{M}, \mathrm{pH}=7.4)$ (for glutathione only) for tissue biochemical estimations. 


\section{Pharmacological assessment}

\section{Assessment of anthropometric parameters}

The body mass index (BMI) [20] and Lee index [21] were assessed as an index of obesity. Body weight and food intake ( $\mathrm{g}$ and $\mathrm{kcal}$ ) were assessed weekly. Weight of liver and different fat depots: epididymal, retroperitoneal and mesenteric fat depots, total weights were also estimated [22].

\section{Assessment of serum biochemical parameters}

The estimation of serum glucose [23]; total cholesterol [24]; high density lipoprotein (HDL) [24], low density lipoprotein LDL-[25]; very low density lipoprotein VLDL [25]; triglycerides [26]; and ALT, AST [27] were carried out spectrophotometrically using biochemical enzymatic kits (Coral Diagnostics Ltd., Mumbai, India).

\section{Serum fatty acid estimation by gas chromatography (GC)} The fatty acid estimation by gas chromatography was done by modified method of Christie [28]. The fatty acid was converted to fatty acid ester. For esterification, $300 \mu \mathrm{l}$ of serum was made upto $3 \mathrm{ml}$ with methanol then 5 drops of concentrated $\mathrm{HCl}$ were added. Final step for esterification was to reflux for $6 \mathrm{hrs}$. After esterification, to $500 \mu \mathrm{l}$ of sample, added $300 \mu \mathrm{l}$ of distilled water and toluene, shaked well and centrifuged for 5 minutes. $1 \mu \mathrm{l}$ of organic solvent was injected into packed column of GC. Standard curve of different FAs was determined using different concentrations: $100-1000 \mu \mathrm{M}$ of oleic and palmitic acids. The conditions for GC were: $40-160$ (10 $\left.{ }^{\circ} \mathrm{C} / \mathrm{min}\right), 160-230\left(5^{\circ} \mathrm{C} / \mathrm{min}\right), 230-240\left(1^{\circ} \mathrm{C} / \mathrm{min}\right)$, and stable for $10 \mathrm{~min}$ at $240 \mathrm{C}$.

\section{Assessment of tissue biochemical parameters}

The tissues were homogenized in $0.1 \mathrm{M}$ tris buffer $(\mathrm{pH} 7.4)$ or $0.1 \mathrm{M}$ phosphate buffer (for glutathione only) using teflon-glass homogenizer. The $10 \%$ liver homogenates were subjected for following tissue biochemical estimations:

\section{Lipid per oxidation (TBARS)}

Lipid per-oxidation was determined by measuring the amounts of malondialdehyde (MDA) produced primarily or thiobarbituric acid reactive substances (TBARS), according to the modified method of Ohkawa et al [29]. Briefly, $0.2 \mathrm{ml}$ of tissue homogenate, $0.2 \mathrm{ml}$ of $8.1 \%$ sodium dodecyl sulphate or sodium lauryl sulphate (SDS/ SLS), $1.5 \mathrm{ml}$ of $20 \%$ acetic acid and $1.5 \mathrm{ml}$ of $8 \%$ TBA were added. The volume of the mixture was made up to $4 \mathrm{ml}$ with distilled water and then heated at $95^{\circ} \mathrm{C}$ on a water bath for 60 min using glass balls as condenser. After incubation the tubes were cooled to room temperature the upper organic layer was taken and its OD read at $532 \mathrm{~nm}$ against an appropriate blank without the sample. The levels of lipid peroxides were expressed as nmoles of thiobarbituric acid reactive sub-stances (TBARS) $\mathrm{nmol} / \mathrm{mg}$ of liver wt.

\section{Reduced glutathione (GSH) [30]}

The homogenate was added with equal volume of $20 \%$ trichloroacetic acid (TCA) containing $1 \mathrm{mM}$ EDTA to precipitate the tissue proteins. The mixture was allowed to stand for $5 \mathrm{~min}$ prior to centrifugation for $10 \mathrm{~min}$ at $200 \mathrm{rpm}$. The supernatant $(200 \mu \mathrm{l})$ was then transferred to a new set of test tubes and added $1.8 \mathrm{ml}$ of the Ellman's reagent $\left(5,5^{\prime}\right.$-dithio bis-2-nitrobenzoic acid) (0.1 mM) was prepared in $0.3 \mathrm{M}$ phosphate buffer with $1 \%$ of sodium citrate solution). Then all the test tubes make upto the volume of $2 \mathrm{ml}$. After completion of the total reaction, the absorbance of the solutions was estimated at $412 \mathrm{~nm}$ against blank. The level of GSH was expressed as $\mu \mathrm{mol} / \mathrm{mg}$ of liver wt.

\section{Nitrite/nitrate level using Greiss reagent [31]}

Tissue nitrite/nitrate was estimated using Greiss reagent which served as an indicator of nitric oxide production. An amount of $100 \mu \mathrm{l}$ Greiss reagent (1:1 solution of $1 \%$ sulphanilamide in 5\% phosphoric acid and $0.1 \%$ napthaylamine diamine dihydrochloric acid in water) was added to $100 \mu \mathrm{l}$ of supernatant and absorbance was measured at $542 \mathrm{~nm}$. Nitrite level was expressed as $\mu \mathrm{mol} / \mathrm{mg}$ of liver wt.

\section{Histopathological study}

The liver and fat depots were excised out, washed in icecold saline, blotted dry and preserved in 10\% formalin solution. The histopathological study was done using hematoxylin and eosin stains and observed under microscope to assess changes in liver tissue and size of fat depots [32,33].

\section{Statistical analysis}

The results were expressed as mean \pm standard deviation (SD) analyzed by one-way and two-way analysis of variance (ANOVA) followed by Bonferroni's multiple comparison test as post hoc analysis. $\mathrm{p}<0.05$ was considered statistically significant.

\section{Results}

\section{Extraction of plant materials}

The yield of methanolic extract of $B$. ceiba Linn stem bark was found to be $4.69 \% \mathrm{w} / \mathrm{w}$. Phytochemical screening of methanolic extract showed the presence of carbohydrate, alkaloids, C-glycosides, cardiac glycosides, saponins glycoside, tannins, terpenoids, steroids and flavonoids constituents. 


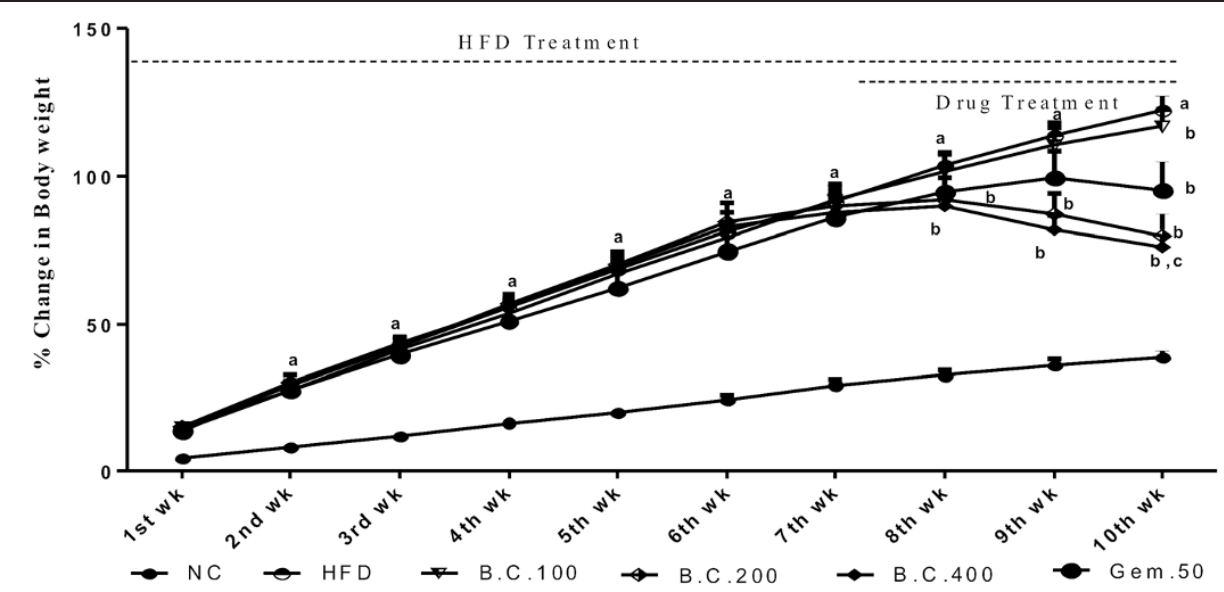

Figure 1 Effect of various pharmacological interventions on body weight; Results were expressed as mean $\pm S D ; a=p<0.05$ vs NC, $\mathrm{b}=\mathrm{p}<0.05$ vs HFD control, $\mathrm{c}=\mathrm{p}<0.05$ vs Gem.50 on respective week.

\section{Acute toxicity study}

B. ceiba extract at the doses of 50,100, 300, 1000, $2000 \mathrm{mg} / \mathrm{kg}$ showed no significant physiological, behavioral and biochemical alterations and was found to be safe, and produced no toxic manifestation and mortality in rats. Hence, the plant extract in doses 100, 200 and $400 \mathrm{mg} / \mathrm{kg}$, p.o. was selected for further pharmacological investigations.

\section{Effect of various pharmacological interventions on} anthropometric parameters

The high fat diet treatment for 10 weeks caused a significant $(\mathrm{p}<0.05)$ increase in \% body wt., BMI, Lee index, liver wt., wt. of fat depots and feed intake (kcal), and decrease in feed intake (g), as compared to normal control rats. Treatment with $B$. ceiba 100, 200 and $400 \mathrm{mg} / \mathrm{kg}$ and gemfibrozil $50 \mathrm{mg} / \mathrm{kg}$ produced significant $(\mathrm{p}<0.05)$ attenuation of these changes caused due to chronic HFD, as compared to HFD control. The effect produced by B. ceiba 200 and $400 \mathrm{mg} / \mathrm{kg}$ was significant greater ( $\mathrm{p}<0.05$ ), as compared to Gem.50, in all these parameters except \% body wt. and feed intake (g and kcal) (Figures 1, 2 and 3) (Table 1).

\section{Effect of various pharmacological interventions on serum} biochemical parameters

The high fat diet treatment for 10 weeks caused a significant $(\mathrm{p}<0.05)$ increase in serum glucose, triglyceride, LDL, VLDL, total cholesterol, free fatty acid, ALT, AST, and decrease in HDL levels, as compared to rats fed on standard chow diet. Treatment with $B$. ceiba extract in three doses, and Gem.50 significantly $(\mathrm{p}<0.05)$ attenuated the increase in the levels of these serum markers, as compared to HFD control. The effect produced by $B$. ceiba $400 \mathrm{mg} / \mathrm{kg}$ was significantly greater than that of Gem-50, in all the parameters (Figure 4) (Table 2).

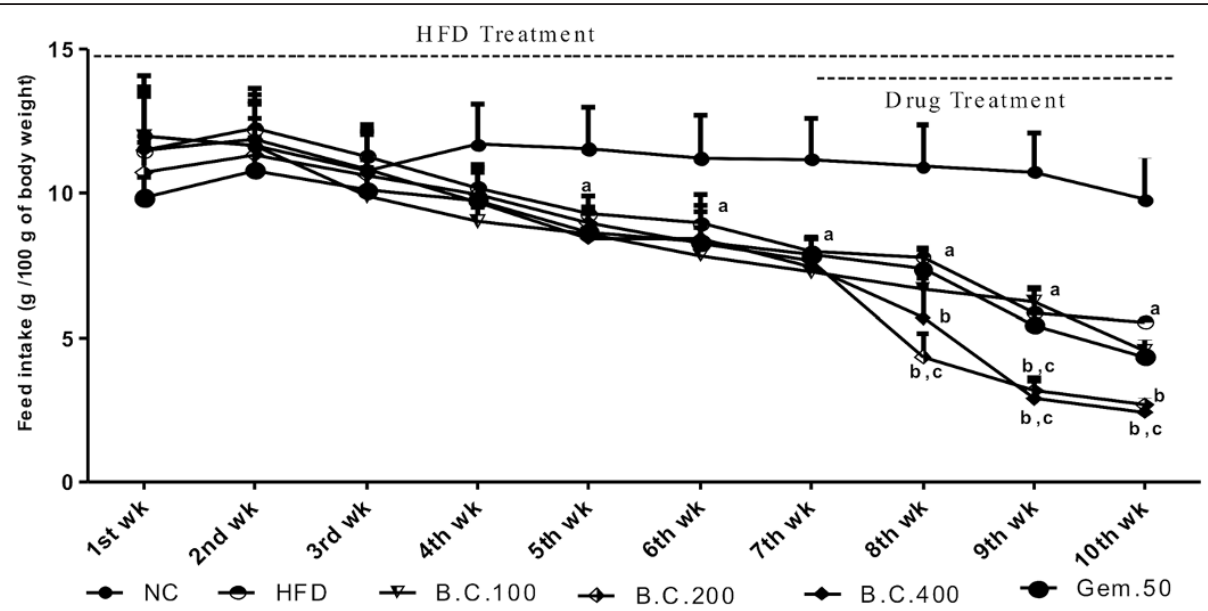

Figure 2 Effect of various pharmacological interventions on feed intake (g/100 $\mathrm{g}$ body $\mathrm{wt})$; Results were expressed as mean $\pm \mathrm{SD}$; $a=p<0.05$ vs NC, $b=p<0.05$ vs HFD control, $c=p<0.05$ vs Gem.50 on respective week. 


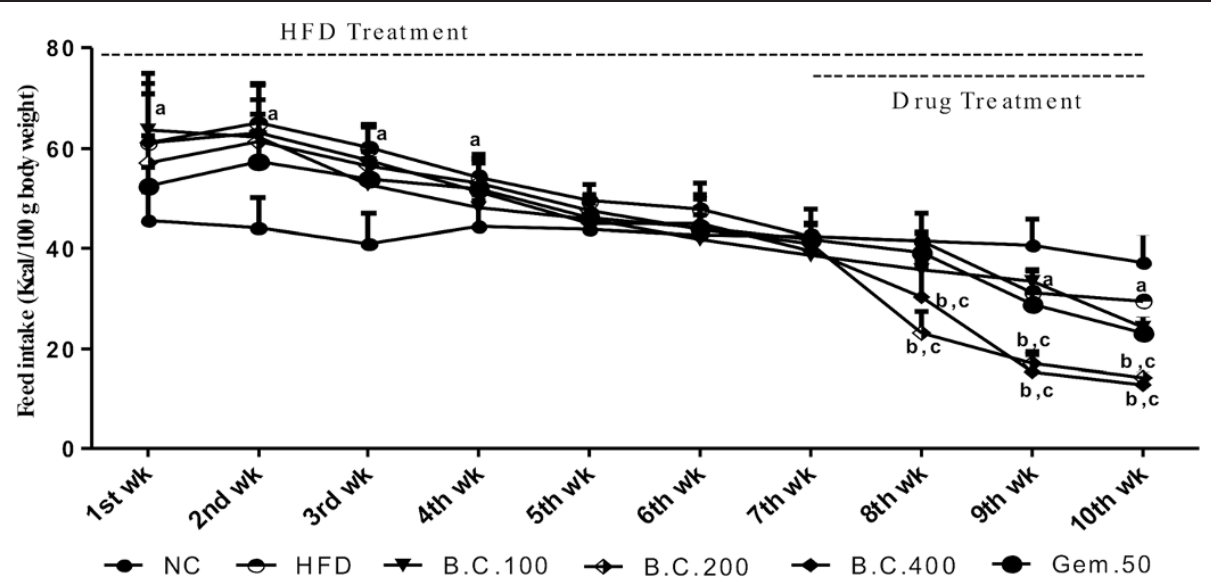

Figure 3 Effect of various pharmacological interventions on feed intake (Kcal); Results were expressed as mean $\pm S D ; a=p<0.05$ vs $\mathrm{NC}, \mathrm{b}=\mathrm{p}<0.05$ vs HFD control, $\mathrm{c}=\mathrm{p}<0.05$ vs Gem.50 on respective week.

Effect of various pharmacological interventions on tissue biochemical markers

HFD treatment for 10 weeks in HFD control rats caused significant $(\mathrm{p}<0.05)$ increase in tissue TBARS, nitrate/ nitrite, and decrease in glutathione levels, as compared to rats fed on standard chow diet. Treatment with $B$. ceiba extract 100, 200 and $400 \mathrm{mg} / \mathrm{kg}$ and Gem.50 produced significant $(\mathrm{p}<0.05)$ attenuation of these toxic changes produced by HFD in the dose dependent manner, as compared to HFD control rats. The effect produced by the plant extract 200 and $400 \mathrm{mg} / \mathrm{kg}$ was significantly greater $(\mathrm{p}<0.05)$ than that produced by Gem.50 in all the parameters (Table 2).

\section{Effect of various pharmacological interventions on histology of liver and adipose tissue}

High fat diet treatment for 10 weeks produced significant changes in hepatic tissue architecture such as micro \& macro vascular steatosis, increased fatty infiltration, inflammation (over activation of kupffer cells), sinusoidal dilation, degeneration of central vein and vacuolization, as compared to normal liver histology. Treatment with B. ceiba 200 and $400 \mathrm{mg} / \mathrm{kg}$ significantly attenuated these effects of HFD, as compared to HFD control. Moreover, HFD treatment for 10 weeks produced significant increase in size of adipocytes: epididymal, retroperitoneal and mesenteric fat depots; as compared to rats fed on standard chow diet. Treatment with B. ceiba extract 200 and $400 \mathrm{mg} / \mathrm{kg}$ and Gem.50 significantly $(\mathrm{p}<0.05)$ decreased the size of adipocytes, as compared to HFD control (Figures 5 and 6).

\section{Discussion}

The present study demonstrated the anti-obesity effect of methanolic extract of Bombax ceiba Linn. against high fat diet-induced obesity in Wistar rats. Gemfibrozil is a lipid lowering agent, involved in metabolism of carbohydrates and fats, as well as adipose tissue differentiation and thereby prevents HFD induced obesity in rodents [34], and thus was used as a standard in present

Table 1 Effect of various pharmacological interventions on anthropometric parameters and weights of fat pads and liver

\begin{tabular}{|c|c|c|c|c|c|c|}
\hline \multicolumn{7}{|c|}{ Anthropometric parameters } \\
\hline Group: & NC & HFD control & B.C. 100 & B.C. 200 & B.C. 400 & Gem.50 \\
\hline BMI & $0.580 \pm 0.0397$ & $1.088 \pm 0.028^{a}$ & $0.882 \pm 0.025^{b}$ & $0.675 \pm 0.071^{b, c}$ & $0.0 .652 \pm 0.054^{b, c}$ & $0.779 \pm 0.028^{b}$ \\
\hline Lee index & $303.51 \pm 10.94$ & $380.9 \pm 4.07^{\mathrm{a}}$ & $342.7 \pm 2.79^{b}$ & $315.97 \pm 15.98^{\mathrm{b}, \mathrm{c}}$ & $313.015 \pm 15.033^{b, c}$ & $332.4 \pm 5.63^{b}$ \\
\hline \multicolumn{7}{|c|}{ Wt. of fat pads and liver wt. (g/100 g of body wt) } \\
\hline Epididymal & $2.13 \pm 0.42$ & $4.583 \pm 0.36^{\mathrm{a}}$ & $3.05 \pm 0.64^{b}$ & $1.3 \pm 0.27^{b, c}$ & $1.28 \pm 0.24^{b, c}$ & $2 \pm 0.48^{b}$ \\
\hline Mesenteric & $1.9 \pm 0.11$ & $4.85 \pm 0.217^{\mathrm{a}}$ & $3.95 \pm 0.38^{b}$ & $2.15 \pm 0.41^{b, c}$ & $2.17 \pm 0.43^{\mathrm{b}, \mathrm{c}}$ & $3.1 \pm 0.66^{\mathrm{b}}$ \\
\hline Retroperitoneal & $1.8 \pm 0.43$ & $5.28 \pm 0.25^{\mathrm{a}}$ & $3.93 \pm 0.197^{b}$ & $2.13 \pm 0.34^{b, c}$ & $2.03 \pm 0.4^{b, c}$ & $3.23 \pm 0.85^{b}$ \\
\hline Total fat pads & $5.83 \pm 0.612$ & $14.72 \pm 0.56^{\mathrm{a}}$ & $10.93 \pm 1.15^{b}$ & $5.58 \pm 0.96^{\mathrm{b}, c}$ & $5.48 \pm 1.03^{b, c}$ & $8.3 \pm 1.93^{b}$ \\
\hline Liver wt. & $7.083 \pm 0.231$ & $13.30 \pm 0.62^{a}$ & $12.98 \pm 0.64$ & $7.48 \pm 0.42^{\mathrm{b}, \mathrm{c}}$ & $7.47 \pm 0.52^{b, c}$ & $12.88 \pm 0.96$ \\
\hline
\end{tabular}




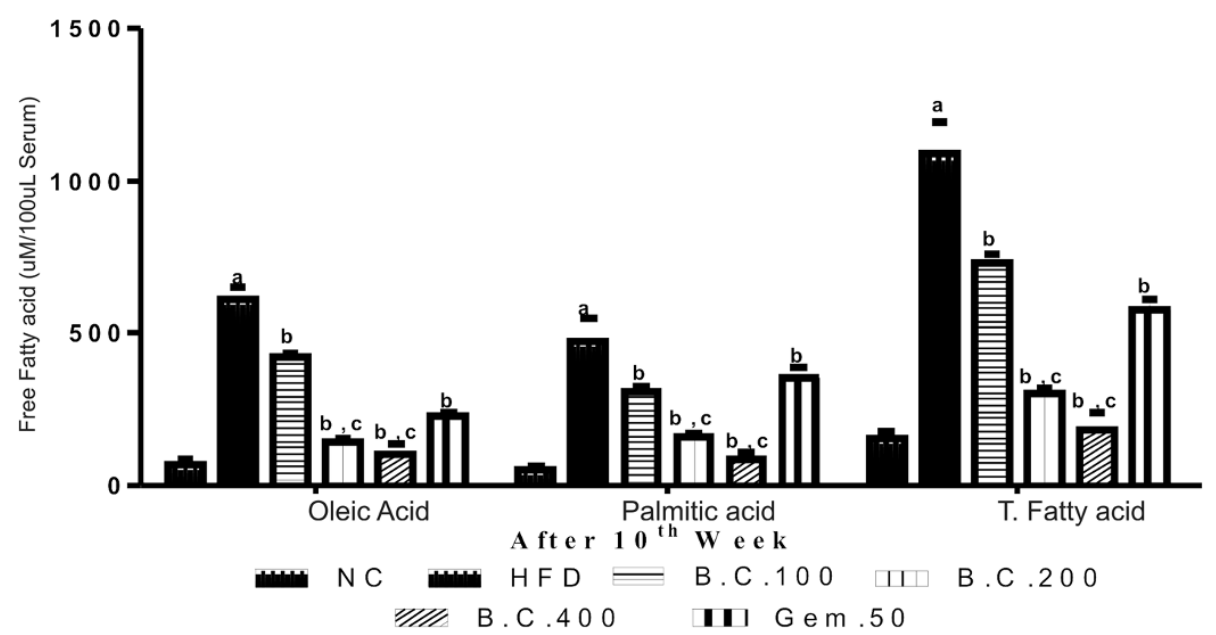

Figure 4 Effect of various pharmacological interventions on free fatty acids; Results were expressed as mean $\pm S D ; a=p<0.05$ vs NC, $\mathrm{b}=\mathrm{p}<0.05$ vs HFD control, $\mathrm{c}=\mathrm{p}<0.05$ vs Gem.50.

study. The experimental reports revealed that the methanolic or hydro-alcoholic extract has marked affinity for the active phytoconstituents of B. ceiba. Hence, the methanolic extract was prepared using soxhlet extractor. Characterization of B. ceiba extract was done in terms of phytochemical screening which signifies the presence of alkaloids, glycosides (cardiac-, saponin- glycosides), tannins, terpenoids, steroids and flavonoids in extract. The plant extract may be standardized for the presence of active phytochemical leads through modern analytical tools: HPLC or HPTLC in future endeavors. The acute toxicity study as per OECD guidelines derives the safe use of medicinal agent and its effects on physiological processes inside the body. Safety assessment is preferred to start with the assessment of biological effects of any bioactive agent. In acute toxicity study, the B. ceiba extract was found to be safe and did not reveal any biological defect and mortality in rodents.

High fat diet induced obesity is a commonly used model for experimental obesity and closely resembles with the symptoms of obesity in humans. HFD induced obesity is characterized by dyslipidemia, hyperglycemia and insulin resistance, increased fat accumulation, impaired glucose metabolism, distinctive visceral adiposity, hyperinsulinemia and hepatic steatosis in rodents $[35,36]$. In present study, high fat diet treatment for 10 weeks produced experimental obesity as evidenced by increased body weight, feed intake (Kcal), wt. of all fat depots, body mass index, Lee index, and decreased feed intake (g). Treatment with different doses of B. ceiba extract and standard drug (gemfibrozil) caused significant attenuation in these changes produced by HFD treatment. This effect

Table 2 Effect of various pharmacological interventions on serum and tissue biochemical parameters

\begin{tabular}{|c|c|c|c|c|c|c|}
\hline \multicolumn{7}{|c|}{ Serum biochemical parameters } \\
\hline Group: & NC & HFD control & B.C. 100 & B.C. 200 & B.C. 400 & Gem.50 \\
\hline Glucose (mg/dl) & $93.65 \pm 13.46$ & $202.25 \pm 4.16^{\mathrm{a}}$ & $177.77 \pm 14.1^{b}$ & $95.8 \pm 9.42^{b, c}$ & $90.8 \pm 6.83^{b, c}$ & $100.3 \pm 5.97^{b}$ \\
\hline $\mathrm{TG}(\mathrm{mg} / \mathrm{dl})$ & $78.9 \pm 11.7$ & $195.54 \pm 10.63^{\mathrm{a}}$ & $138.94 \pm 5.8^{b}$ & $114.9 \pm 11.75^{\mathrm{b}, \mathrm{c}}$ & $98.7 \pm 7.83^{b, c}$ & $128.4 \pm 15.3^{b}$ \\
\hline $\mathrm{TC}(\mathrm{mg} / \mathrm{dl})$ & $57.9 \pm 4.8$ & $343.42 \pm 15.54^{\mathrm{a}}$ & $169.889 \pm 9.81^{b}$ & $95 \pm 6.1^{b, c}$ & $93.12 \pm 7.9^{b, c}$ & $94.93 \pm 7.3^{b}$ \\
\hline LDL (mg/dl) & $8.99 \pm 5.42$ & $289.76 \pm 15.2^{\mathrm{a}}$ & $120.83 \pm 8.95^{b}$ & $26.45 \pm 5.65^{b, c}$ & $13 \pm 4.36^{b, c}$ & $15.1 \pm 6.9^{b}$ \\
\hline VLDL (mg/dl) & $15.78 \pm 2.3$ & $39.11 \pm 2.12^{\mathrm{a}}$ & $27.79 \pm 1.17^{b}$ & $22.98 \pm 2.4^{b, c}$ & $19.74 \pm 1.6^{b, c}$ & $25.7 \pm 3.1^{b}$ \\
\hline $\mathrm{HDL}(\mathrm{mg} / \mathrm{dl})$ & $33.13 \pm 5.5$ & $14.55 \pm 1.9^{\mathrm{a}}$ & $21.28 \pm 5.84^{b}$ & $45.57 \pm 8.4^{b, c}$ & $60.37 \pm 3.1^{b, c}$ & $54.14 \pm 5.1^{b}$ \\
\hline ALT (IU/L) & $50.75 \pm 6.6$ & $153.26 \pm 7.35^{\mathrm{a}}$ & $94.28 \pm 5.65^{b}$ & $67.9 \pm 4.9^{b, c}$ & $50.8 \pm 4.9^{\mathrm{b}, \mathrm{c}}$ & $71.8 \pm 4.64^{b}$ \\
\hline AST (IU/L) & $66.4 \pm 6.7$ & $160.83 \pm 6.56^{\mathrm{a}}$ & $107.86 \pm 9.6^{b}$ & $65.38 \pm 7.1^{b, c}$ & $50.25 \pm 5.1^{b, c}$ & $87.5 \pm 12.4^{b}$ \\
\hline \multicolumn{7}{|c|}{ Tissue biochemical parameters } \\
\hline TBARS & $0.6 \pm 0.31$ & $4.93 \pm 0.64^{a}$ & $3.9 \pm 0.77^{b}$ & $1.83 \pm 0.7^{\mathrm{b}, \mathrm{c}}$ & $1.53 \pm 0.7^{b, c}$ & $4.03 \pm 0.71^{b}$ \\
\hline Nitrite/nitrate & $0.74 \pm 0.4$ & $2.6 \pm 0.1^{a}$ & $1.63 \pm 0.04^{b}$ & $0.98 \pm 0.1^{b, c}$ & $0.89 \pm 0.69^{\mathrm{b}, c}$ & $1.61 \pm 0.02^{b}$ \\
\hline Glutathione & $2.05 \pm 0.25$ & $0.19 \pm 0.8^{\mathrm{a}}$ & $0.42 \pm 0.07^{b}$ & $1.8 \pm 0.21^{b, c}$ & $1.99 \pm 0.16^{\mathrm{b}, \mathrm{c}}$ & $0.55 \pm 0.11^{b}$ \\
\hline
\end{tabular}




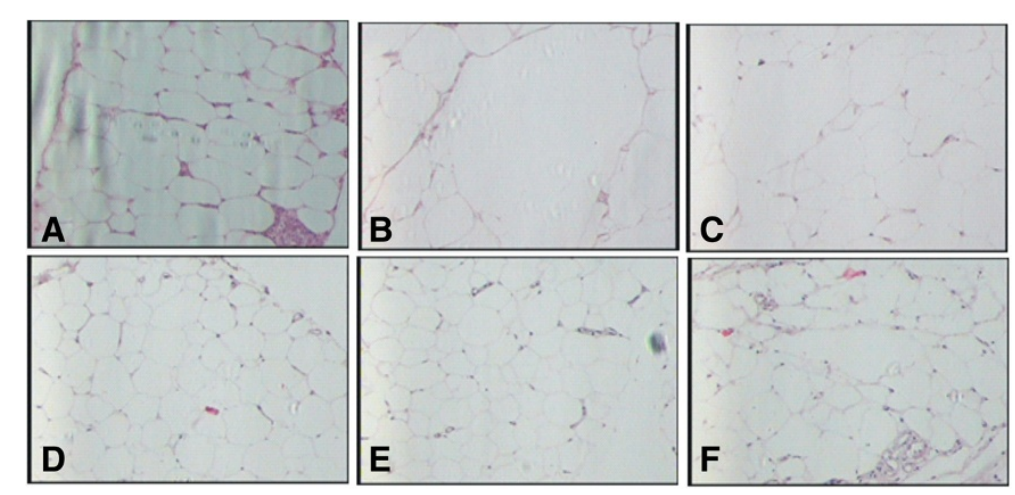

Figure 5 Effect of various pharmacological interventions on histology of adipose tissues; (A) NC, (B) HFD, (C) B.C. 100, (D) B.C. 200, (E) B.C. 400 and (F) Gem.50.

may be due to the prevention of pathological mechanisms responsible for excessive fat accumulation, dyslipidemia and weight gain, possibly by increasing leptin sensitivity, providing anorexic effect, and increasing energy expenditure.

Lipogenesis up-regulation in HFD induced experimental obesity leads to elevated serum lipids [37] and decreased HDL levels in obese rats [36]. Further, it also produces hyperglycemia. The Free fatty acid level is reported to be increased during HFD induction [38]. It further caused liver damage and the increased level of hepatic serum markers like ALT and AST [39]. In present study, these serum markers have been modulated with chronic induction of HFD for 10 weeks as the markers of hyperlipidemia, dyslipidemia, hyperglycemia, and liver toxicity. On treatment with three consecutive doses of $B$. ceiba extract and gemfibrozil significantly reversed the effects of HFD treatment on these serum parameters. This may be due to the inactivation of acetyl-coA carboxylase (ACC), as a result of AMPK activation that mediates thermogenesis and FAS inhibition [15], which further inhibit the proximal and rate limiting steps of fatty acid oxidation [40]. This may derive the efficacy of $B$. ceiba's to reduce circulating lipids, free fatty acids and thereby prevent fatty liver [41].
The increased fatty acid levels in chronically HFD fed rats is a characteristic marker caused due to the dysregulation of insulin and leptin signaling and stimulation of PTP-1B. These processes may be arrested by the administration of $B$. ceiba extract in rats and hence corrected the pharmacological interventions underlying the HFD induced obesity, as evidenced by the concentration of fatty acid content in biological fluid. These observations may be supported by the literatures revealing the efficacy of flavonoids isolated from B. ceiba extract having FAS inhibitory activity [15]. Moreover, the Lupeol, a triterpenoid, is a major constituent of stem bark of B. ceiba has inhibitory effect on PTP-1B, and thereby prevents TG synthesis and accumulation of lipids in adipocytes [16]. On the basis of the observations, it may be hypothesized that there is a possible modulation of FAS and PTP-1B signaling in protective effect of $B$. ceiba extract against HFD induced obesity and this may be due to the potency and efficacy of reported active phytoconstituents present in it.

Oxidative stress is greatly increased on the treatment with high fat diet in the form of enhanced lipid peroxidation reactions and depletion of tissue antioxidant like
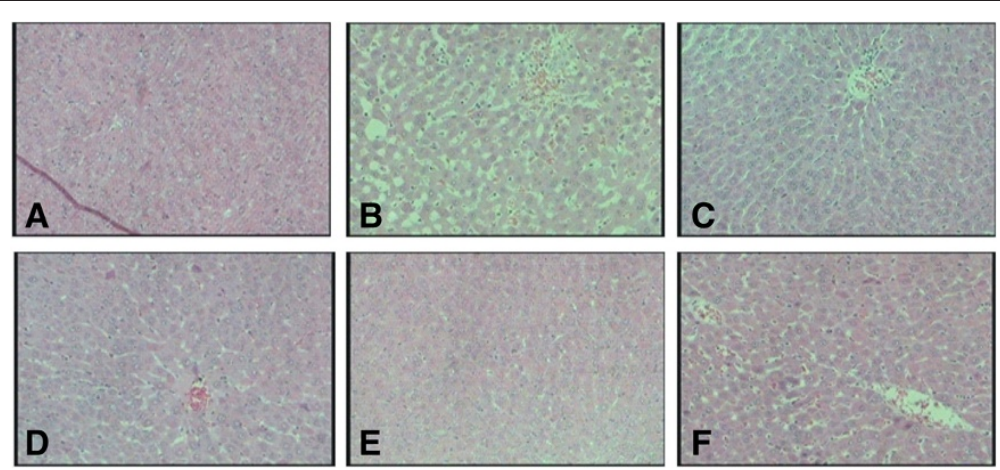

Figure 6 Effect of various pharmacological interventions on histology of liver tissue; (A) NC, (B) HFD, (C) B.C. 100, (D) B.C. 200, (E) B.C. 400 and (F) Gem.50. 
GSH; and higher nitrostative stress, in men [39]. In present study, increased TBARS and nitrite/nitrate, and decreased GSH levels confirm the role of oxidative and nitrostative stresses. Treatment with B. ceiba extract 100, 200 and $400 \mathrm{mg} / \mathrm{kg}$ significantly attenuated these HFD induced oxidative/nitrosative stress, and this effect was more pronounced, in comparison to standard drug: gemfibrozil. Moreover, another report documented the free radical scavenging property of $B$. ceiba [13]. Therefore, the anti-oxidative efficacy of $B$. ceiba may contribute for the amelioration of experimental obesity and hepatic insufficiencies in rats. In most of the pharmacological assessments, the biological efficacy of $B$. ceiba extract was more pronounced as compared to the standard drug: Gemfibrozil. These findings may infer that the methanolic extract of $B$. ceiba contain active phytoconstituents in higher concentration or acting synergistically to attain potent biological efficacy which was comparable to that of gemfibrozil. The future studies may lend support for the biological potency of isolated active phytoconstituentss like Lupeol, Shamimin etc of B. ceiba in sub-maximal therapeutic dosage and their comparative safe evaluation with reported lipid lowering agent. The findings of present investigation signifies the use of low dose of active phytoconstituent isolated from $B$. ceiba as much effective and may be devoid of any toxic effect on chronic administration in comparison to the reported lipid lowering agent.

Hepatic steatosis is a common consequence of obesity, and its prevalence [39] has been further characterized with hepatic fat accumulation and increase in size and wt of adipose masses in the body [42]. By increased liver steatosis, fatty infiltration, inflammation through Kupffer cell activation and size of adipose tissues epididymal, peritoneal, mesenteric fat depots and histological characteristics in present study as also observed in histological imagining. Various doses of B. ceiba and standard drug significantly reversed the effect of HFD on liver adipose tissues and liver steatosis, liver weight and adipose tissue size was increased during HFD treatment. Moreover extent of tissue architecture damage due to chronic HFD treatment was prevented by $B$. ceiba ext. effectively.

Therefore, in present study, the observed decrease in free fatty acid level may be due to the inhibition of FAS activity and TG synthesis, and PTP-1B activity. The antioxidant effect may also contribute to the anti-obesity potential of Bombax ceiba Linn. in Wistar rats.

\section{Conclusion}

The results obtained in present study may conclude that the extract of stem bark of Bombax ceiba Linn. has significant anti-obesity potential against HFD induced experimental obesity, possibly due to modulation of FAS and PTP-1B signaling in Wistar rats due to the presence of active flavanoids and lupeol respectively.

\section{Abbreviations}

HFD: High fat diet; FAS: Fatty acid synthase; PTP-1B: Protein tyrosine phosphatase-1B; ALT: Alanine transferase; AST: Aspartate transferase.

\section{Competing interests}

The authors declare that they have no competing interests.

\section{Authors' contributions}

RG and PS designed the experimental protocol. PG, YC and RG carried out the experimentation and drafted the manuscript. RG and PS performed the statistical analysis and interpreted the results. All authors read and approved the final manuscript.

\section{Acknowledgment}

Authors are thankful to the management, ISF College of Pharmacy, Moga, Punjab for providing research facilities and kind support.

\section{Author details}

${ }^{1}$ Department of Pharmacology, ISF College of Pharmacy, Moga 142001 India. 'School of Pharmaceutical Sciences, Shoolini University, Solan, HP 173212, India.

Received: 31 December 2012 Accepted: 25 September 2013 Published: 25 October 2013

\section{References}

1. Grill H, Ginsberg A, Seeley R, Kaplan J: Brainstem application of melanocortin receptor ligands produces long-lasting effects on feeding and body weight. J Neurosci 1998, 18:10128-10135.

2. Haslam DW, James WP: Obesity. Lancet 2005, 366:1197-1209.

3. Wilding JP: Neuropeptides and appetite control. Diabet Med 2001, 19:619-627.

4. Zammit VA, Waterman IJ, Topping D, McKay G: Insulin stimulation of hepatic triacylglycerols secretion and the etiology of insulin resistance. J Nutr 2001, 131:2074-2077.

5. Klaman LD, Boss O, Peroni OD, Kim JK, Martino JL, Zabolotny JM, Moghal N, Lubkin M, Kim YB, Sharpe AH: Increased energy expenditure, decreased adiposity, and tissue-specic insulin sensitivity in protein-tyrosine phosphatase 1B-decient mice. Mol Cell Biol 2000, 20:5479-5489.

6. Sharma H, Chandola HM: Ayurvedic concept of obesity, metabolic syndrome, and diabetes mellitus. J Altern Complem Med 2011, 17:549-552.

7. Verma V, Jalalpure SS, Sahu A, Bhardwaj LK, Prakesh Y: Bombax ceiba Linn: pharmacognostical, phytochemistry, ethnobotany, and pharmacology studies. Int Pharm Sci 2011, 1:62-68.

8. Young-jae Y, Nguyen-Hai N, Young K, Byung-Zun A: Antiangiogenic activity of lupeol from Bombax ceiba stems bark. Phyto Reas 2003, 17(4):341-344.

9. Saleem R, Ahmad M, Hussain SA, Qazi AM, Ahmad SI: Hypotensive, hypoglycemic and toxicology studies on the flavonol C-glycoside shamimin from Bombax ceiba. Planta Med 1999, 65:331-334.

10. Dar A, Faizi S, Naqvi S, Roome T, Zikrur-Rehman S, Ali M, Firdous S, Moin ST: Analgesic and antioxidant activity of mangiferin and its derivatives: the structure activity relationship. Biol Pharm Bull 2005, 28:596-600.

11. Singh V, Pandey RP: Ethanobotany of Rajasthan India, scientific publishers. Jodhpur 1998, 63:58-59.

12. Karnick CR: Ethnobotanical records of drug plants described in valmiki Ramayana and their uses in the ayurvedic system of medicine. Quart J Crude Drug Res 1975, 13:143-154.

13. Jain V, Verma SK, Katewa SS, Anandjiwala S, Sing B: Free radical scavenging property of Bombax ceiba Linn. root. Res J Med Plant 2011, 5:462-470.

14. Kumar S: Evaluation of RBC membrane stabilization and antioxidant activity of Bombax ceiba in an in vitro method. Int J Pharma and Bio Sci 2011, 2:1.

15. Chen J, Zhuang D, Cai W, Xu L, Li E, Wu Y, Sugiyama K: Inhibitory effects of four plants flavonoids extracts on fatty acid synthase. J Environ Sci 2009, 21:S131-S134

16. Hata K, Hori K, Murata J, Takahashi S: Remodeling of actin cytoskeleton in lupeol induced B16 2F2 cell differentiation. J Biochem 2005, 138(4):467-472. 
17. Harborne JB: Phytochemical methods. London: Chapman and Hall; 1998:1-254. 3.

18. Botham PA: Acute systemic toxicity prospects for tiered testing strategies. Toxicol in Vitro 2004, 18:227-230.

19. Shrinivasan K, Viswanad B, Asrat L, Kaul CL, Ramarao P: Combination of high-fat-diet and low-dose steptozotocin-trated rat: a model for type 2 diabetes and pharmacological screening. Pharmacol Res 2005, 52:313-320

20. Novellie LB, Dinij YS, Galhardi CM, Ebaid GMX, Rodrigues HG, Main F, Fernandes AAH, Cicogna AC, Novellifilho JLVB: Anthropometrical parameters and markers of obesity in rats. Lab Animals 2007, 41:111-119.

21. Bernardis LL: Prediction of carcass fat, waterand lean body mass from Lee's nutritive ratio in rats with hypothalamic obesity. Experientia 1970 26:789-790.

22. Ainsline DA, Proietto J, Fam BC, Thormburn AW: Short-term, high-fat diet low circulating leptin concentration in rats. Am J Clin Nutr 2000, 71:438-442.

23. Trinder K, Hiraga Y, Nakamura N, Kitajo A, Linuma F: Determination of glucose in blood using glucose oxidase-peroxidien. Chem Phem Bulletin 1969, 27:568-570.

24. Allain CC, Poon LS, Chan CS, Richmond W, Fu PC: Enzymatic determination of total serum cholesterol. Clin Chem 1974, 20:470-475.

25. Friedewal WT, Levy RI, Fredrickson DS: Estimation of the concentration of low-density lipoprotein in cholesterol in plasma, without use of the preparative ultracentrifuge. Cin Chem 1972, 18:499-502.

26. Werner M, Gabrielson DG, Eastman J: Ultramicro determination of serum triglyceride by bioluminescent assay. Clin Chem 1981, 27:268-271.

27. Clin J: IFCC method for the measurement of catalytic concentration of enzyme. Chem Clin Biochem 1986, 24:497.

28. Christie WW: Preparation of ester derivatives of fatty acids for chromatographic analysis. In Advances in Lipid Methodology. Edited by Christie WW. Dundee: Oily Press; 1993:69-111. 2.

29. Ohkawa H, Ohishi N, Yagi K: Assay for lipid peroxides in animal tissues by thiobarbituric acid reaction. Anal Biochem 1979, 95:351.

30. Ellman GL: Tissue sulphydryl groups. Arch Biochem Biophys 1959, 82:70-77.

31. Green LC, Wagner DA, Glogowski J, Skipper PL, Wishnok JS, Tannenbaum SR: Analysis of nitrate, nitrite, and nitrate in biological samples. Anal Biochem 1982, 126:131-138.

32. Buettner $R$, Parhofer $K G$, Woenckhaus $M$, Wrede CE, Kunz-Schughart LA, Scholmerich J, Bollheimer LC: Defining high fat diet rat models: metabolic and molecular effects of different fat types. J Mol Endocrinol 2006, 36:485-501.

33. Chen HC, Farese RVJ: Determination of adipocyte size by computer image analysis. J Lipid Res 2002, 43:986-989.

34. Toruner F, Akbay E, Cakir N, Sancak B, Elbeg S, Taneri F, Aktürk M, Karakoç A, Ayva ZG, Arslan M: Effects of PPAR gamma and PPAR alpha agonists on serum leptin levels in diet-induced obese rats. Horm Metab Res 2004, 36:226-230.

35. Pang J, Choi Y, Park T: llex paraguariensis exart ameliorate obesity induced by high fat diet: potential rale of AMPK in the visceral adipose tissue. Arch Biochem Biophys 2008, 476(2):178-185.

36. Woods SC, Seeley RJ, Rushing PA, D'Alessio D, Tso PA: Controlled high fat diet induced an obese syndrome in rats. J Nutr 2003, 133:1081-1087.

37. Storlien LH, Jenkins AB, Chisholm DJ, Pascoe WS, Khouri S, Kraegen EW: Influence of dietary fat composition on development of insulin resistance in rats. Relationship to muscle triglyceride and n-3 fatty acids in muscle phospholipids. Diabetes 1991, 40(2):280-289.

38. Gil-Campos M, Canete R, Gil A: Hormones regulating lipid metabolism and plasma lipids in childhood obesity. Int J Obes Relat Metab Disord 2003, 3:S75-S80.

39. Wanless IR, Lentz JS: Fatty liver hepatitis (steatohepatitis) and obesity: an autopsy study with analysis of risk factors. Hepatology 1990, 12:1106-1110
40. Unger RH: The physiology of cellular liporegulation. Annu Rev Physiol 2003, 65:333-347.

41. Hyashi T, Hirshman MF, Kurth EJ, Winder WW, Goodyear LJ: Evidence for $5^{\prime}$ AMP-activated protein kinase mediation of the effect of muscle contraction on glucose transport. Diabetes 1998, 47:1369-1373.

42. Day CP, James OF: Steatohepatitis: a tale of two hits. Gastroenterology 1998, 114:842-845.

doi:10.1186/1472-6882-13-281

Cite this article as: Gupta et al:: Possible modulation of FAS and PTP-1B signaling in ameliorative potential of Bombax ceiba against high fat diet induced obesity. BMC Complementary and Alternative Medicine 2013 13:281.

\section{Submit your next manuscript to BioMed Central and take full advantage of:}

- Convenient online submission

- Thorough peer review

- No space constraints or color figure charges

- Immediate publication on acceptance

- Inclusion in PubMed, CAS, Scopus and Google Scholar

- Research which is freely available for redistribution

Submit your manuscript at www.biomedcentral.com/submit
() Biomed Central 